\title{
APPLICATIONS OF OUTER MEASURES TO SEPARATION PROPERTIES OF LATTICES AND REGULAR OR $(-$-SMOOTH MEASURES
}

\author{
PAO-SHENG HSU \\ University of Maine \\ Orono, Maine 04669-5752 \\ (Received March 1, 1994 and in revised torm June 18, 1994)
}

\begin{abstract}
Associated with a $0-1$ measure $\mu \in \mathrm{I}(\mathscr{S})$ where $\mathscr{L}$ is a lattice of subsets of $\mathrm{X}$ are outer measures $\mu^{\prime}$ and $\tilde{\mu}$; associated with a $\sigma$-smooth $0-1$ measure $\mu \in \mathrm{I}_{\sigma}(\mathscr{L})$ is an outer measure $\mu^{\prime \prime}$ or with $\mu \in \mathrm{I}_{o}\left(\mathscr{S}^{\prime}\right), \mathscr{L}^{\prime}$ being the complementary lattice, another outer measure $\tilde{\tilde{\mu}}$. These outer measures and their associated measurable sets are used to establish separation properties on $\mathscr{L}$ and regularity and $\sigma$-smoothness of $\mu$. Separation properties between two lattices $\mathscr{L}_{1}$ and $\mathscr{L}_{2}, \mathscr{L}_{1} \subseteq \mathscr{L}_{2}$, are similarly investigated. Notions of strongly $\sigma$-smooth and slightly regular measures are also used.
\end{abstract}

KEY WORDS AND PHRASES. Normal lattice, semi-separates, separates, complement generated, countably paracompact, countably compact. Regular, $\sigma$-smooth, strongly $\sigma$-smooth, slightly regular measures; $\mu^{*}$-measurable sets.

1992 AMS SUBJECT CLASSIFICATION CODES. 28A12, $28 \mathrm{C} 15$.

\section{INTRODUCTION.}

Let $\mathrm{X}$ be a set, $\mathscr{L}$ a lattice of subsets of $\mathrm{X}$ such that $\varnothing$ and $\mathrm{X}$ belong to $\mathscr{L}$ and $\mathrm{A}(\mathscr{L})$ denote the algebra generated by $\mathscr{L}$. The set $\mathrm{I}(\mathscr{L})$ consists of all two-valued (zero or one) finitely additive measures on $\mathbf{A}(\mathscr{L})$; the set $\mathrm{I}_{\mathrm{R}}(\mathscr{L})$ is a subset of $\mathrm{I}(\mathscr{L})$ in which a measure $\mu$ is $\mathscr{L}$-regular; the set $\mathrm{I}_{\sigma}(\mathscr{L})$ consists of those elements in $\mathrm{I}(\mathscr{L})$ which are $\sigma$-smooth on $\mathscr{L}$. Analogous definitions hold for $\mathscr{L}^{\prime}$, the complementary lattice to $\mathscr{L}$.

Associated with $\mu \in \mathrm{I}(\mathscr{L})$ and $\mu \in \mathrm{I}_{o}(\mathscr{L})$ are outer measures $\mu^{\prime}, \tilde{\mu}$ and $\mu^{\prime \prime}$, and with $\mu \in \mathrm{I}_{o}\left(\mathscr{L}^{\prime}\right), \tilde{\tilde{\mu}}$. These outer measures have been investigated to some extent in $[4,5,6]$.

In this paper, we show how these outer measures can be used systematically to establish separation properties between lattices, and also for establishing regularity of measures or the domination of a suitable measure on $\mathscr{L}$ by a regular $\sigma$-smooth measure. In order to achieve some of these goals, we must investigate conditions involving the equality of some of these outer measures on various lattices.

In section 2, we introduce the notations and background material needed for the paper and begin our consideration of separation properties. Section 3 is concerned mainly with lattice-topological conditions which will guarantee equality of certain outermeasures and which will yield regularity. Section 4 extends the work of [4] in considering slightly regular measures on $\mathscr{L}$ and their properties. In addition, specific characteristics are given for the various measurable sets associated with the given outer measures. These, in turn, lead to results on measures in $\mathrm{I}_{\mathrm{R}}(\mathscr{L}) \cap \mathrm{I}_{\mathrm{o}}(\mathscr{L})$, as well as to measures dominated by such regular measures. 
Our notations and terminology are consistent with standard usage (see, for example, $[1,3,8]$ ).

\section{BACKGROUND AND NOTATIONS.}

In this section we consider certain lattice properties and definitions, as well as notations. We summarize the most important ones that will be used throughout the paper for the reader's convenience. Related matters can be found in $[2,4,5,6,7]$.

The set $\mathbf{M}(\mathscr{\varphi})$ consists of finite and finitely additive (non-negative) measures on $\mathbf{A}(\mathscr{S}) ; \mathrm{I}(\mathscr{L})$ mentioned in section 1 is a subset of $\mathbf{M}(\mathscr{L})$. The set $\mathrm{M}_{\mathrm{R}}(\mathscr{L})$ is a subset of $\mathrm{M}(\mathscr{L})$ where $\nu \in \mathbf{M}_{\mathrm{R}}(\mathscr{L})$ is said to be regular on $\mathscr{L}$, or $\underline{\varphi}$-regular if and only if $\nu(\mathrm{A})=\sup \{\nu(\mathrm{L}) \mid \mathrm{L} \subseteq \mathrm{A}, \mathrm{L} \in \mathscr{Q}\}$, for $\mathrm{A} \in \mathrm{A}(\mathscr{L})$; again, $\mathrm{I}_{\mathrm{R}}(\mathscr{L}) \subseteq \mathrm{M}_{\mathrm{R}}(\mathscr{L})$. We say that $\mu$ is a measure on $\mathscr{L}$ instead of on $\mathbf{A}(\mathscr{Q})$ by convention. Also, if $\mathscr{L}$ is a lattice, $\mathscr{L}^{\prime}=\left\{\mathrm{L}^{\prime}: \mathrm{L} \in \mathscr{L}\right\}$ denotes the complementary lattice.

We note that since there exists a one-to-one correspondance between prime $\mathscr{S}_{\text {-filters }}$ and elements of $\mathrm{I}(\mathscr{L})$, and similarly between $\mathscr{L}$-ultrafilters and elements of $\mathrm{I}_{\mathrm{R}}(\mathscr{\mathscr { L }})$, it follows that:

(1) For any $\mu \in \mathrm{I}(\mathscr{L})$, there exists $\rho \in \mathrm{I}_{\mathrm{R}}(\mathscr{L})$ such that $\mu \leq \rho$ on $\mathscr{L}$.

(2) For any $\mu \in \mathrm{I}(\mathscr{L})$, there exists $\lambda \in \mathrm{I}_{\mathrm{R}}\left(\mathscr{L}^{\prime}\right)$ such that $\mu \leq \lambda$ on $\mathscr{L}^{\prime}$.

We next associate two finitely subadditive outer measures $\mu^{\prime}$ and $\tilde{\mu}$ with each $\mu \in \mathbf{M}(\mathscr{L})$. Let $\mu \in \mathrm{M}(\mathscr{L})$, define for $\mathrm{E} \subseteq \mathrm{X}$

$$
\mu^{\prime}(E)=\inf \left\{\boldsymbol{\mu}\left(L^{\prime}\right) \mid E \subseteq L^{\prime}, L \in \mathscr{L}\right\} .
$$

Then it is easy to see that $\mu^{\prime}(\varnothing)=0, \mu^{\prime}$ is monotone, $\mu^{\prime}$ is finitely subadditive, and $\mu \leq \mu^{\prime}(\mathscr{L})$, i.e., $\mu \leq \mu^{\prime}$ on $\mathscr{L}$, and $\mu=\mu^{\prime}\left(\mathscr{L}^{\prime}\right)$. Finally, $\mu=\mu^{\prime}(\mathscr{L})$ if and only if $\mu \in \mathrm{M}_{\mathrm{R}}(\mathscr{L})$. Dually, for $\mu \in \mathrm{M}(\mathscr{L})$, define for $\mathrm{E} \subseteq \mathrm{X}$

$$
\tilde{\mu}(E)=\inf \{\mu(L) \mid E \subseteq L, L \in \mathscr{L}\} .
$$

$\tilde{\mu}$ is also a finitely subadditive outer measure; $\mu=\tilde{\mu}(\mathscr{L}) ; \mu \leq \tilde{\mu}\left(\mathscr{L}^{\prime}\right) ; \mu=\tilde{\mu}\left(\mathscr{L}^{\prime}\right)$ if and only if $\mu \in \mathbf{M}_{\mathrm{R}}\left(\mathscr{L}^{\prime}\right)$.

In this paper, we will be concerned with the special case of $\mu \in \mathrm{I}(\mathscr{L})$ in the above. We list several important facts; details can be found in $[4,5,6]$.

A lattice $\mathscr{L}$ is normal if for $\mathrm{L}_{1}$ and $\mathrm{L}_{2}$ in $\mathscr{L}, \mathrm{L}_{1} \cap \mathrm{L}_{2}=\varnothing$, there exist $\mathrm{L}_{3}$ and $\mathrm{L}_{4}$ in $\mathscr{L}$ such that $\mathrm{L}_{1} \subseteq \mathrm{L}_{3}{ }^{\prime}, \mathrm{L}_{2} \subseteq \mathrm{L}_{4}{ }^{\prime}$ and $\mathrm{L}_{3}{ }^{\prime} \cap \mathrm{L}_{4}{ }^{\prime}=\varnothing$. Equivalently, in terms of measures, $\mathscr{L}$ is normal if and only if for a $\mu \in \mathrm{I}(\mathscr{L}), \nu_{1}, \nu_{2} \in \mathrm{I}_{\mathrm{R}}(\mathscr{L}), \mu \leq \nu_{1}(\mathscr{L})$ and $\mu \leq \nu_{2}(\mathscr{L})$ imply that $\nu_{1}=\nu_{2}$.

PROPOSITION 2.1. If $\mathscr{L}$ is a normal lattice, and if $\nu \in \mathrm{I}(\mathscr{L})$ and $\mu \in \mathrm{I}_{\mathrm{R}}(\mathscr{L})$ with $\nu \leq \mu(\mathscr{L})$, then $\nu^{\prime}=\mu^{\prime}(\mathscr{L})$. Conversely if a lattice $\mathscr{L}$ has this property, then it is normal.

For lattices $\mathscr{L}_{1}$ and $\mathscr{L}_{2}$ of subsets of $\mathrm{X}, \mathscr{L}_{1} \subseteq \mathscr{L}_{2}, \mathscr{L}_{1}$ semi-separates $\mathscr{L}_{2}$ if for $\mathrm{L}_{1} \in \mathscr{L}_{1}$, $\mathrm{L}_{2} \in \mathscr{L}_{2}, \mathrm{~L}_{1} \cap \mathrm{L}_{2}=\varnothing$, there exists $\mathrm{L}_{0} \in \mathscr{L}_{1}$ such that $\mathrm{L}_{2} \subseteq \mathrm{L}_{0}$ and $\mathrm{L}_{1} \cap \mathrm{L}_{0}=\varnothing$. The following fact is less well-known; we give a slightly different proof.

PROPOSITION 2.2. Let $\mathscr{L}_{1} \subseteq \mathscr{L}_{2}$ be lattices of subsets of $\mathrm{X}$, then $\mathscr{L}_{1}$ semi-separates $\mathscr{L}_{2}$ if and only if for any $\mu \in \mathrm{I}_{\mathrm{R}}\left(\mathscr{L}_{1}\right), \mu^{\prime}=\tilde{\mu}\left(\mathscr{L}_{2}\right)$.

PROOF. a. For any $\mathrm{L}_{1} \in \mathscr{L}_{1}$ with $\mathrm{L}_{2} \subseteq \mathrm{L}_{1}{ }^{\prime}$, there exists $\tilde{\mathrm{L}}_{1} \in \mathscr{L}_{1}$ such that $\mathrm{L}_{2} \subseteq \tilde{\mathrm{L}}_{1} \subseteq \mathrm{L}_{1}{ }^{\prime}$, $\mu\left(\tilde{\mathrm{L}}_{1}\right) \leq \mu\left(\mathrm{L}_{1}{ }^{\prime}\right)$, so $\tilde{\mu}\left(\mathrm{L}_{2}\right) \leq \mu^{\prime}\left(\mathrm{L}_{2}\right)$. For any $\tilde{\mathrm{L}}_{1}$ with $\mathrm{L}_{2} \subseteq \tilde{\mathrm{L}}_{1} \in \mathscr{L}_{1} \subseteq \mathscr{L}_{2}$, , we have $\mu^{\prime}\left(\mathrm{L}_{2}\right) \leq \mu^{\prime}\left(\tilde{\mathrm{L}}_{1}\right)=\mu\left(\tilde{\mathrm{L}}_{1}\right)$; so $\mu^{\prime}\left(\mathrm{L}_{2}\right) \leq \tilde{\mu}\left(\mathrm{L}_{2}\right)$.

b. Suppose not: there exist $\mathrm{L}_{2} \in \mathscr{L}_{2}$ and $\mathrm{L}_{1} \in \mathscr{L}_{1}$, such that $\mathrm{L}_{1} \cap \mathrm{L}_{2}=\varnothing$, and for any $\tilde{\mathrm{L}}_{1} \supseteq \mathrm{L}_{2}$ where $\tilde{\mathrm{L}}_{1} \in \mathscr{L}_{1}, \tilde{\mathrm{L}}_{1} \cap \mathrm{L}_{1} \neq \varnothing$. The set $\mathbf{S}=\left\{\tilde{\mathrm{L}}_{1} \cap \mathrm{L}_{1}: \tilde{\mathrm{L}}_{1} \supseteq \mathrm{L}_{2}\right\}$ consisting of non- 
empty sets is non-empty: $X \supseteq L_{2}$ and $X \cap L_{1} \neq \varnothing$, so $X \cap L_{1} \in S$. We see that $S$ has finite intersection property, i.e., every finite intersection of sets in $\mathbf{S}$ is non-empty: Suppose $\tilde{L}_{1} \cap L_{1}$ and $\hat{L}_{1} \cap L_{1}$ are in $\mathbf{S},\left(\tilde{L}_{1} \cap \mathrm{L}_{1}\right) \cap\left(\hat{\mathrm{L}}_{1} \cap \mathrm{L}_{1}\right)=\left(\tilde{\mathrm{L}}_{1} \cap \hat{\mathrm{L}}_{1}\right) \cap \mathrm{L}_{1} \neq \varnothing$ since $\tilde{\mathrm{L}}_{1} \cap \hat{\mathrm{L}}_{1} \supseteq \mathrm{L}_{2}$. There exists $\mu \in \mathrm{I}_{\mathrm{R}}\left(\mathscr{S}_{1}\right)$ such that $\mu\left(\tilde{\mathrm{L}}_{1} \cap \mathrm{L}_{1}\right)=1$ for all $\tilde{\mathrm{L}}_{1} \cap \mathrm{L}_{1}$ in $\mathbf{S}$. Since both $\tilde{\mathrm{L}}_{1}$ and $\mathrm{L}_{1}$ contain $\tilde{\mathrm{L}}_{1} \cap \mathrm{L}_{1}$, $\mu\left(\tilde{L}_{1}\right)=\mu\left(\mathrm{L}_{1}\right)=1$ for a 11 L $\tilde{L}_{1} \supseteq \mathrm{L}_{2}$, the outer measure $\mu^{\prime}\left(\mathrm{L}_{2}\right)=\inf \left\{\mu\left(\mathrm{A}_{1}\right) \mid \mathrm{L}_{2} \subseteq \mathrm{A}_{1}, \mathrm{~A}_{1} \in \mathscr{L}_{1}\right\}=1$ by assumption. But $\mathrm{L}_{2} \subseteq \mathrm{L}_{1}{ }^{\prime}$ and $\mu\left(\mathrm{L}_{1}{ }^{\prime}\right)=0$, implying that $\mu^{\prime}\left(\mathrm{L}_{2}\right)=0$, a contradiction.

Again, let $\mathscr{S}_{1} \subseteq \mathscr{L}_{2}$. We recall that every $\mu \in \mathrm{I}_{\mathrm{R}}\left(\mathscr{L}_{1}\right)$ can be extended to a $\nu \in \mathrm{I}_{\mathrm{R}}\left(\mathscr{L}_{2}\right)$. Also if $\rho \in \mathrm{I}_{\mathrm{R}}\left(\mathscr{L}_{2}\right)$ and if $\mathscr{L}_{1}$ semi-separates $\mathscr{L}_{2}$, then $\left.\rho\right|_{\mathbf{A}\left(\mathscr{L}_{1}\right)} \in \mathrm{I}_{\mathrm{R}}\left(\mathscr{L}_{1}\right)$.

PROPOSITION 2.3. Suppose $\mathscr{L}_{1} \subseteq \mathscr{L}_{2}$ and $\mu \in \mathrm{I}_{\mathrm{R}}\left(\mathscr{L}_{1}\right)$ is extended to $\nu \in \mathrm{I}_{\mathrm{R}}\left(\mathscr{L}_{2}\right)$. Then $\nu$ is $\underline{\mathscr{L}}_{1}$-regular on $\mathscr{L}_{2-}^{\prime}$ (i.e., for any $\mathrm{L}_{2}{ }^{\prime}$ in $\mathscr{L}_{2}$, if $\nu\left(\mathrm{L}_{2}{ }^{\prime}\right)=1$, there exists $\tilde{\mathrm{L}}_{1} \subseteq \mathrm{L}_{2}{ }^{\prime}$ with $\nu\left(\tilde{\mathrm{L}}_{1}\right)=1$ ) if and only if $\nu=\mu^{\prime}\left(\mathscr{L}_{2}\right)$.

PROOF. a. For any $\mathrm{L}_{2} \in \mathscr{L}_{2}, \nu\left(\mathrm{L}_{2}\right)=\nu^{\prime}\left(\mathrm{L}_{2}\right) \leq \mu^{\prime}\left(\mathrm{L}_{2}\right)$ since $\mathscr{L}_{1} \subseteq \mathscr{L}_{2}$ and $\nu=\mu\left(\mathscr{L}_{1}\right)$. If $\nu^{\prime}\left(\mathrm{L}_{2}\right)=0$ for some $\mathrm{L}_{2} \in \mathscr{L}_{2}$, then $\nu\left(\mathrm{L}_{2}\right)=0$ by regularity. With $\nu\left(\mathrm{L}_{2}^{\prime}\right)=1$, there is an $\mathrm{L}_{1} \in \mathscr{L}_{1}$, $\mathrm{L}_{1} \subseteq \mathrm{L}_{2}{ }^{\prime}$ and $\nu\left(\mathrm{L}_{1}\right)=1=\mu\left(\mathrm{L}_{1}\right)$. Now $\mathrm{L}_{2} \subseteq \mathrm{L}_{1}{ }^{\prime}$, so $\mu^{\prime}\left(\mathrm{L}_{2}\right)=0$.

b. Assume that $\mathrm{L}_{2}^{\prime} \in \mathscr{L}_{2}$ and $\nu\left(\mathrm{L}_{2}{ }^{\prime}\right)=1$. Then $\nu\left(\mathrm{L}_{2}\right)=0=\mu^{\prime}\left(\mathrm{L}_{2}\right)$. There is $\mathrm{L}_{1} \in \mathscr{L}_{1}$, $\mathrm{L}_{2} \subseteq \mathrm{L}_{1}{ }^{\prime}$ and $\mu\left(\mathrm{L}_{1}{ }^{\prime}\right)=0$, so $\mathrm{L}_{1} \subseteq \mathrm{L}_{2}{ }^{\prime}$ and $\nu\left(\mathrm{L}_{1}\right)=1$.

That $\nu=\mu^{\prime}\left(\mathscr{L}_{2}\right)$ is equivalent to a separation property. When $\mathscr{L}_{1} \subseteq \mathscr{L}_{2}$, we say that $\underline{\mathscr{L}}_{1}$ separates $\mathscr{L}_{2}$ if for $\mathrm{B}_{1}$ and $\mathrm{B}_{2}$ in $\mathscr{L}_{2}, \mathrm{~B}_{1} \cap \mathrm{B}_{2}=\varnothing$, there exist $\mathrm{A}_{1}$ and $\mathrm{A}_{2}$ in $\mathscr{L}_{1}$ such that $\mathrm{B}_{1} \subseteq \mathrm{A}_{1}$, $\mathrm{B}_{2} \subseteq \mathrm{A}_{2}$ and $\mathrm{A}_{1} \cap \mathrm{A}_{2}=\varnothing$. If $\mathscr{L}_{1} \subseteq \mathscr{L}_{2}, \mathscr{L}_{1}$ separates $\mathscr{L}_{2}$ implies that $\mathscr{L}_{1}$ semi-separates $\mathscr{L}_{2}$.

PROPOSITION 2.4. The condition that $\mathscr{L}_{1}$ separates $\mathscr{L}_{2}$ is equivalent to: For every $\mu \in \mathrm{I}_{\mathrm{R}}\left(\mathscr{L}_{1}\right)$ and every extension $\nu \in \mathrm{I}_{\mathrm{R}}\left(\mathscr{L}_{2}\right)$, we have (i) $\nu=\mu^{\prime}\left(\mathscr{L}_{2}\right)$ and (ii) $\mu^{\prime}=\tilde{\mu}\left(\mathscr{L}_{2}\right)$.

PROOF. a. We will show that $\mathscr{L}_{1}$ separates $\mathscr{L}_{2}$ implies that $\nu$ is $\mathscr{L}_{1}$-regular on $\mathscr{L}_{2}^{\prime}$ : Suppose that $\nu\left(\mathrm{L}_{2}^{\prime}\right)=1, \mathrm{~L}_{2} \in \mathscr{L}_{2}$, then there exists $\tilde{\mathrm{L}}_{2} \in \mathscr{L}_{2}$ such that $\tilde{\mathrm{L}}_{2} \subseteq \mathrm{L}_{2}^{\prime}$ and $\nu\left(\tilde{\mathrm{L}}_{2}\right)=1$ since $\nu \in \mathrm{I}_{\mathrm{R}}\left(\mathscr{L}_{2}\right)$. There is then $\mathrm{L}_{1} \in \mathscr{L}_{1}$ such that $\mathrm{L}_{2} \subseteq \mathrm{L}_{1}, \tilde{\mathrm{L}}_{2} \subseteq \tilde{\mathrm{L}}_{1}$ and $\mathrm{L}_{1} \cap \tilde{\mathrm{L}}_{1}=\varnothing$ by the separation property. Now $\tilde{\mathrm{L}}_{1} \subseteq \mathrm{L}_{1}{ }^{\prime} \subseteq \mathrm{L}_{2}{ }^{\prime} ; \tilde{\mathrm{L}}_{2} \subseteq \tilde{\mathrm{L}}_{1}$ and $\nu\left(\tilde{\mathrm{L}}_{2}\right)=1$, therefore $\nu\left(\tilde{\mathrm{L}}_{1}\right)=1$, the measure being defined on $\mathscr{L}_{1}$. By proposition $2.3, \nu=\mu^{\prime}\left(\mathscr{L}_{2}\right)$. Since $\mathscr{L}_{1}$ separates $\mathscr{L}_{2}$, part (ii) follows from proposition 2.2 .

b. The proof that $\mathscr{L}_{1}$ separates $\mathscr{L}_{2}$ is analogous to that of part b of proposition 2.2. If $\mathscr{L}_{1}$ does not separate $\mathscr{L}_{2}$, then a set with finite intersection property can be constructed to lead to a contradiction.

An immediate application of some of the previous material can be given (see $[5,6]$ for further applications).

PROPOSITION 2.5. If $\mathrm{I}(\mathscr{L})=\mathrm{I}_{\mathrm{R}}(\mathscr{L})$, then $\mathscr{L}$ semi-separates $\mathbf{A}(\mathscr{L})$, which is equivalent to $\mathscr{L}=\mathscr{L}^{\prime}$.

PROOF. If $\mathrm{I}(\mathscr{L})=\mathrm{I}_{\mathrm{R}}(\mathscr{L})$, one can show that $\mathrm{I}_{\mathrm{R}}(\mathscr{L})=\mathrm{I}_{\mathrm{R}}\left(\mathscr{L}^{\prime}\right)$. Then for $\mu \in \mathrm{I}_{\mathrm{R}}\left(\mathscr{L}^{\prime}\right), \mathrm{A} \in \mathbf{A}(\mathscr{L})$, $\mu(\mathrm{A})=\inf \{\mu(\mathrm{L}) \mid \mathrm{A} \subseteq \mathrm{L}, \mathrm{L} \in \mathscr{L}\}=\tilde{\mu}(\mathrm{A})$ and $\mu=\mu^{\prime}$ on $\mathbf{A}\left(\mathscr{L}^{\prime}\right)=\mathbf{A}(\mathscr{L})$. Therefore, $\mu^{\prime}(\mathrm{A})=\tilde{\mu}(\mathrm{A})$; by proposition $2.2, \mathscr{L}$ semi-separates $\mathrm{A}(\mathscr{L})$.

We will show that in that case $\mathscr{L} \subseteq \mathscr{L}^{\prime}$ (therefore $\mathscr{L}^{\prime} \subseteq \mathscr{L}^{\prime \prime}=\mathscr{L}$ ): Let $\mathrm{L}_{1} \in \mathscr{L}$, then $\mathrm{L}_{1}=\mathrm{L}_{2} \in \mathbf{A}(\mathscr{L})$ and $\mathrm{L}_{1} \cap \mathrm{L}_{1}{ }^{\prime}=\varnothing$. There exists $\mathrm{L}_{0} \in \mathscr{L}$ such that $\mathrm{L}_{1}{ }^{\prime} \subseteq \mathrm{L}_{0}$ and $\mathrm{L}_{1} \cap \mathrm{L}_{0}=\varnothing$. We have $\varnothing=\mathrm{L}_{1} \cap \mathrm{L}_{1}{ }^{\prime} \subseteq \mathrm{L}_{1} \cap \mathrm{L}_{0}=\varnothing$, hence $\mathrm{L}_{1}{ }^{\prime}=\mathrm{L}_{0} \in \mathscr{L}$. 
We now consider the case where $\mu \in \mathrm{I}(\mathscr{Y})$ has additional smoothness properties. A measure

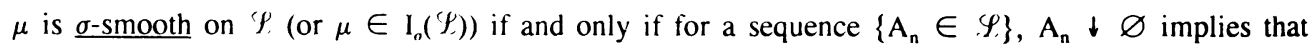
$\lim _{n \rightarrow \infty} \mu\left(A_{n}\right)=0$. Define for $\mu \in \mathrm{I}_{o}(\mathscr{\varphi}), \mathrm{E} \subseteq \mathrm{X}$,

$$
\mu^{\prime \prime}(E)=\inf \left\{\sum_{1}^{\infty} \mu\left(L_{1}{ }^{\prime}\right) \mid E \subseteq U_{L_{1}}{ }^{\prime}, L_{1} \in \mathscr{L}\right\} .
$$

It follows immediately that $\mu^{\prime \prime}$ is an outermeasure (countably subadditive). In addition:

(1) $\mu \leq \mu^{\prime \prime}(\mathscr{Q})$.

(2) $\mu^{\prime \prime} \leq \mu^{\prime}$.

(3) $\mu^{\prime \prime} \leq \mu\left(\mathscr{Q}^{\prime}\right)$.

(4) If $\mu$ is $\mathscr{L}$-regular and $\sigma$-smooth on $\mathscr{L}$ (denoted by $\mu \in I_{\mathrm{R}}^{\sigma}(\mathscr{L})$ ), then $\mu=\mu^{\prime \prime}=\mu^{\prime}(\mathscr{L})$ and $\mu^{\prime \prime}=\mu^{\prime}=\mu\left(\mathscr{L}^{\prime}\right)$.

Dually, using a covering from $\mathscr{L}$, instead of from $\mathscr{L}^{\prime}$, we define for $\mu \in \mathrm{I}_{o}\left(\mathscr{L}^{\prime}\right), \mathrm{E} \subseteq \mathrm{X}$,

Then we have:

$$
\tilde{\tilde{\mu}}(E)=\inf \left\{\sum_{1=1}^{\infty} \mu\left(L_{1}\right) \mid E \subseteq \bigcup_{1}^{\infty} L_{i}, L_{i} \in \mathscr{L}\right\} \text {. }
$$

(1) $\tilde{\tilde{\mu}} \leq \mu(\mathscr{L})$.

(2) If $\mu \in \mathrm{I}_{o}\left(\mathscr{L}^{\prime}\right)$, then $\mu \leq \tilde{\tilde{\mu}}\left(\mathscr{L}^{\prime}\right)$.

3. SOME TOPOLOGICAL-TYPE CONDITIONS ON $\mathscr{L}$ FOR $\mu^{\prime}=\mu^{\prime \prime}$ ON $\mathscr{L}^{\prime}$ OR $\mathscr{L}$.

We will first see that when $\mathscr{L}$ is complement generated, the $\sigma$-smoothness on $\mathscr{L}^{\prime}$ of a measure $\mu$ will yield $\mathscr{L}$-regularity. Then we will introduce a stronger version of $\sigma$-smoothness so that we may obtain $\mathscr{L}$-regularity from the strong $\sigma$-smoothness on $\mathscr{L}$ and some topological conditions on $\mathscr{L}$. This strong $\sigma$-smoothness will also yield the equality of the two outer measures $\mu^{\prime}$ and $\mu^{\prime \prime}$ on $\mathscr{L}^{\prime}$.

A lattice $\mathscr{L}$ is complement generated if for any $\mathrm{L} \in \mathscr{L}$, there exists a sequence $\left\{\mathrm{L}_{\mathrm{n}} \in \mathscr{L}\right\}$ such that $L=\bigcap_{n=1}^{\infty} L_{n}{ }^{\prime}$. A lattice $\mathscr{L}$ is countably paracompact if for any sequence $\left\{A_{n} \in \mathscr{L}\right\}, A_{n} \downarrow \varnothing$, there exists $\left\{L_{n} \in \mathscr{L}\right\}$ such that $A_{n} \subseteq L_{n}{ }^{\prime}$ and $L_{n}{ }^{\prime} \downarrow \varnothing$. If $\mathscr{L}$ is complement generated, it is countably paracompact.

NOTE. If $\mathscr{L}$ is countably paracompact, then $\mathrm{I}_{o}\left(\mathscr{L}^{\prime}\right) \subseteq \mathrm{I}_{o}(\mathscr{L})$.

It is our aim throughout the paper to give consistently applications of the outermeasures that we have introduced. The following is well-known (see $[4,5,6])$, but we give an alternate proof using outermeasures.

PROPOSITION 3.1. If $\mathscr{L}$ is complement generated and $\mu \in \mathrm{I}_{o}\left(\mathscr{L}^{\prime}\right)$, then $\mu \in \mathrm{I}_{\mathrm{R}}^{o}(\mathscr{L})$.

PROOF. $\mathscr{L}$ is countably paracompact and therefore $\mu \in \mathrm{I}_{o}(\mathscr{L})$ by the above note. We have $\tilde{\tilde{\mu}} \leq \mu \leq \mu^{\prime \prime} \leq \mu^{\prime}(\mathscr{L})$. Suppose that for some $\mathrm{L} \in \mathscr{L}, \tilde{\tilde{\mu}}(\mathrm{L})=0$ and $\mu^{\prime}(\mathrm{L})=1$. Let $\mathrm{L}=\bigcap_{\mathrm{n}=1} \mathrm{~L}_{\mathrm{n}}{ }^{\prime}$ where $\mathrm{L}_{\mathrm{n}} \in \mathscr{L}$ for all $\mathrm{n}$. Then $\mu\left(\mathrm{L}_{\mathrm{n}}{ }^{\prime}\right)=1$ for all $\mathrm{n}$, otherwise $\mu\left(\mathrm{L}_{\mathrm{N}}{ }^{\prime}\right)=0$ for some $\mathrm{N}$ would imply that $\mu^{\prime}(\mathrm{L}) \leq \mu^{\prime}\left(\mathrm{L}_{\mathrm{N}}\right)=0$. Now $\mathrm{L}^{\prime}=\bigcup_{\mathrm{n}} \mathrm{L}_{\mathrm{n}}$ and $\mu\left(\mathrm{L}_{\mathrm{n}}\right)=0$ for all $\mathrm{n}$ means that $\tilde{\tilde{\mu}}\left(\mathrm{L}^{\prime}\right)=0$. Then $\tilde{\tilde{\mu}}(\mathrm{X})=0$, contradicting that $\mu \in \mathrm{I}_{o}\left(\mathscr{L}^{\prime}\right)$. Therefore, $\tilde{\tilde{\mu}}=\mu^{\prime}(\mathscr{L})$ and $\mu=\mu^{\prime}(\mathscr{L})$; so $\mu \in \mathrm{I}_{\mathrm{R}}^{o}(\mathscr{L})$.

We consider two more notions of $\sigma$-smoothness, digress to examine their properties and make some comparisons. A measure $\mu \in \mathrm{I}(\mathscr{L})$ is strongly $\sigma$-smooth on $\mathscr{L}$ or $\mu \in \Phi(\mathscr{L})$ if and only if for any sequence $\left\{L_{n} \in \mathscr{L}\right\}, L_{n} \downarrow$, if $\bigcap_{n} L_{n} \in \mathscr{L}$ then $\mu\left(\bigcap_{n} L_{n}\right)=\inf _{n} \mu\left(L_{n}\right)=\lim _{n \rightarrow \infty} \mu\left(L_{n}\right)$. A measure $\mu \in \mathrm{I}(\mathscr{L})$ is $\underline{\sigma \text {-smooth on } \mathbf{A}(\mathscr{L})}$ or $\mu \in \mathrm{I}^{\circ}(\mathscr{L})$ if and only if for any sequence $\left\{\mathrm{A}_{\mathrm{n}} \in \mathbf{A}(\mathscr{L})\right\}$, if $\mathrm{A}_{\mathrm{n}} \downarrow \varnothing$. then $\lim _{n \rightarrow \infty} \mu\left(A_{n}\right)=0$. 
Notes on $\sigma$-smoothness:

(1) $\mu \in \mathrm{I}^{\prime \prime}(\mathcal{\varphi})$ if and only if $\mu$ is countably additive on $\mathbf{A}\left(\varphi^{(}\right)$.

(2) $I^{o}(\mathscr{L}) \subseteq \Phi(\mathscr{L}) \subseteq \mathrm{I}_{o}(\mathcal{P})$.

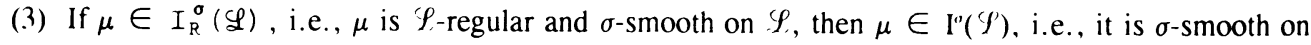
$\mathbf{A}(\mathscr{P})$.

(4) a. If $\mu \in \mathrm{I}\left(\mathscr{S}^{\prime}\right)$ is countably subadditive on $\mathscr{L}^{\prime}$ ( i.e., for all sequences $\left\{\mathrm{L}_{n}^{\prime} \in \mathscr{Q}^{\prime}\right\}$, $\left.\mu\left(\bigcup_{\mathrm{n}} L_{\mathrm{n}}{ }^{\prime}\right) \leq \sum_{\mathrm{n}} \mu\left(\mathrm{L}_{\mathrm{n}}{ }^{\prime}\right)\right)$ and $\bigcup_{\mathrm{n}} L_{\mathrm{n}}{ }^{\prime} \in \mathscr{L}^{\prime}$, then $\mu \in \Phi(\mathscr{L})$.

b. If $\mu \in \Phi(\mathscr{L})$, then $\mu$ is countably subadditive on $\mathscr{L}^{\prime}$.

Hence, countably subadditivity on $\mathscr{\varphi}^{\prime}$ is equivalent to strongly $\sigma$-smoothness on $\mathscr{\varphi}$.

PROOF. a. Suppose $L_{n} \downarrow \bigcap_{n} L_{n}=L \in \mathscr{L}$ and $\mu\left(L_{n}\right)=1$. By assumption, $\mu\left(\cup_{\mathrm{n}} L_{n}{ }^{\prime}\right) \leq \sum_{\mathrm{n}} \mu\left(\mathrm{L}_{\mathrm{n}}{ }^{\prime}\right)=0$; so $\mu\left(\mathrm{L}^{\prime}\right)=0$. Therefore, $\mu(\mathrm{L})=1$ and $\mu\left(\bigcap_{\mathrm{n}} \mathrm{L}_{\mathrm{n}}\right)=\inf _{\mathrm{n}} \mu\left(\mathrm{L}_{\mathrm{n}}\right)$.

b. Suppose that for $\left\{L_{n}^{\prime} \in \mathscr{L}^{\prime}\right\}, \mu\left(\cup_{n} L_{n}{ }^{\prime}\right)=1$, then $\mu\left(\cap_{n} L_{n}\right)=0$. We may assume that $L_{n} \downarrow$, then $\lim _{n \rightarrow \infty} \mu\left(L_{n}\right)=0$ since $\mu \in \Phi(\mathscr{L})$. As a result, $\mu\left(L_{1}^{\prime}\right)=1$ from some $N$ on, so the inequality holds.

(5) a. If $\mu \in \mathrm{I}_{o}(\mathscr{L})$ and $\mu^{\prime \prime}=\mu^{\prime}\left(\mathscr{L}^{\prime}\right)$, then $\mu \in \Phi(\mathscr{L})$.

b. If $\mu \in \Phi(\mathscr{L})$, then $\mu^{\prime \prime}=\mu^{\prime}\left(\mathscr{L}^{\prime}\right)$.

PROOF. See [4].

Dually, we have:

(6) a. If $\mu \in \mathrm{I}_{o}\left(\mathscr{L}^{\prime}\right)$ and $\tilde{\tilde{\mu}}=\mu(\mathscr{L})$, then $\mu \in \Phi\left(\mathscr{L}^{\prime}\right)$.

b. If $\mu \in \Phi\left(\mathscr{L}^{\prime}\right)$, then $\tilde{\tilde{\mu}}=\mu(\mathscr{L})$.

Again, the following proposition is known, but we give an alternate proof using outermeasures.

PROPOSITION 3.2. If $\mathscr{L}$ is complement generated and normal, $\mu \in \Phi(\mathscr{L})$, then $\mu \in \mathrm{I}_{\mathrm{R}}(\mathscr{L})$ and therefore $\mu \in I_{R}^{\sigma}(\mathscr{L})$.

PROOF. We have $\mu \leq \mu^{\prime \prime} \leq \mu^{\prime}(\mathscr{L})$ and $\mu=\mu^{\prime}\left(\mathscr{L}^{\prime}\right)$ in general. Since $\mu \in \Phi(\mathscr{L})$, by Note (5), $\mu^{\prime \prime}=\mu^{\prime}=\mu\left(\mathscr{L}^{\prime}\right)$. Suppose that for some $\mathrm{L} \in \mathscr{L}, \mu(\mathrm{L})=0$ and $\mu^{\prime}(\mathrm{L})=1$; let $\mathrm{L}=\bigcap_{\mathrm{n}} \mathrm{L}_{\mathrm{n}}{ }^{\prime}$ where $\mathrm{L}_{\mathrm{n}} \in \mathscr{L}$. By normality, there exist $\mathrm{A}_{\mathrm{n}}$ and $\mathrm{B}_{\mathrm{n}}$ in $\mathscr{L}$ such that $\mathrm{L} \subseteq \mathrm{A}_{\mathrm{n}}{ }^{\prime} \subseteq \mathrm{B}_{\mathrm{n}} \subseteq \mathrm{L}_{\mathrm{n}}{ }^{\prime}$ for all $\mathrm{n}$, so $\mathrm{L}=\bigcap_{\mathrm{n}} \mathrm{A}_{\mathrm{n}}{ }^{\prime}=\bigcap_{\mathrm{n}} \mathrm{B}_{\mathrm{n}}=\bigcap_{\mathrm{n}} \mathrm{L}_{\mathrm{n}}{ }^{\prime}$. Since $\mu^{\prime}(\mathrm{L})=1, \mu\left(\mathrm{A}_{\mathrm{n}}{ }^{\prime}\right)=1$ for all $\mathrm{n}$; so $\mu\left(\mathrm{A}_{\mathrm{n}}\right)=0$ and $\mu\left(\mathrm{B}_{\mathrm{n}}{ }^{\prime}\right)=0$ for all n. But $L^{\prime}=\bigcup_{\mathrm{n}} B_{\mathrm{n}}{ }^{\prime}$, so $\mu^{\prime \prime}\left(\mathrm{L}^{\prime}\right)=0$. Also, $\mu\left(\mathrm{L}^{\prime}\right)=1$ and $\mu=\mu^{\prime \prime}\left(\mathscr{L}^{\prime}\right)$ implies that $\mu^{\prime \prime}\left(\mathrm{L}^{\prime}\right)=1$, a contradiction.

To summarize, we have equality of the two outer measures $\mu^{\prime \prime}$ and $\mu^{\prime}$ on $\mathscr{L}^{\prime}$ and $\mathscr{L}$ if a. $\mathscr{L}$ is complement generated, $\mu \in \mathrm{I}_{\sigma}\left(\mathscr{L}^{\prime}\right)$ or b. $\mathscr{L}$ is complement generated and normal, $\mu \in \Phi(\mathscr{L})$.

Next, we show

PROPOSITION 3.3. If $\mathscr{L}$ is normal, $\mu \in \mathrm{I}_{o}(\mathscr{L}), \nu \in \mathrm{I}_{\mathrm{R}}(\mathscr{L})$ and $\mu \leq \nu(\mathscr{L})$, then $\nu \in \mathrm{I}_{o}\left(\mathscr{L}^{\prime}\right)$.

PROOF. Suppose that there is a sequence $\left\{\mathrm{L}_{\mathrm{n}} \in \mathscr{L}\right\}, \mathrm{L}_{\mathrm{n}} \downarrow \varnothing$ and $\nu\left(\mathrm{L}_{\mathrm{n}}{ }^{\prime}\right)=1$ for all $\mathrm{n}$. Since $\nu \in \mathrm{I}_{\mathrm{R}}(\mathscr{L})$, there exists $\tilde{\mathrm{L}}_{\mathrm{n}} \in \mathscr{L}$ such that $\tilde{\mathrm{L}}_{\mathrm{n}} \subseteq \mathrm{L}_{\mathrm{n}}{ }^{\prime}$ and $\nu\left(\tilde{\mathrm{L}}_{\mathrm{n}}\right)=1$ for all $\mathrm{n}$. Using normality and an argument analogous to the one used in the proof of proposition 3.2, we arrive at a contradiction that $\mu \in \mathrm{I}_{o}(\mathscr{L})$.

It is easy to see that if $\mathscr{L}$ is a $\delta$-lattice (i.e., closed under coutable intersections), and if $\mu \in \Phi(\mathscr{L})$, then $\mu^{\prime \prime}(\mathrm{E})=\mu^{\prime}(\mathrm{E})$ for all $\mathrm{E} \subseteq \mathrm{X}$.

If we only assume that $\mu \in \mathrm{I}_{o}(\mathscr{L})$, then we must impose topological type conditions $\mathscr{L}$ to insure that $\mu^{\prime \prime}=\mu^{\prime}(\mathscr{L})$. We have 
PROPOSITION 3.4. Let $\mu \in \mathrm{I}_{o}(\mathscr{\varphi})$, then $\mu^{\prime \prime}=\mu^{\prime}(\mathscr{\varphi})$

(a) if $\mathscr{Y}$ is normal and a $\delta$-lattice; or

(b) if $\mathscr{\varphi}$ is normal and countably paracompact; or

(c) if $\mathscr{Y}$ is countably compact (i.e., every countable covering of $\mathrm{X}$ by elements from $\mathscr{S}^{\prime}$ has a finite subcovering).

PROOF. a. Suppose $\mu^{\prime \prime}(\mathrm{H})=0$ and $\mu^{\prime}(\mathrm{H})=1$ for some $\mathrm{H} \in \mathscr{\varphi}$. There exists $\left\{\mathrm{L}_{\mathrm{n}} \in \mathscr{Y}_{\}}\right\}$, $\mathrm{H} \subseteq \bigcup_{\mathrm{n}} \mathrm{L}_{\mathrm{n}}{ }^{\prime}, \mathrm{L}_{\mathrm{n}}{ }^{\prime} \uparrow, \mu\left(\mathrm{L}_{\mathrm{n}}{ }^{\prime}\right)=0$ for all $\mathrm{n}$. Since $\mathscr{L}$. is a $\delta$-lattice, $\bigcup_{\mathrm{n}} \mathrm{L}_{\mathrm{n}}{ }^{\prime}=\mathrm{L}^{\prime}$ where $\mathrm{L}=\bigcap_{\mathrm{n}} \mathrm{L}_{\mathrm{n}} \in \mathscr{L}$. Using normality analogous to the proof of proposition 3.2, we arrive at a contradiction that $\mu$ is $\sigma$ smooth on $\mathscr{P}$.

b. As a measure, $\mu$ is dominated by some $\nu \in \mathrm{I}_{\mathrm{R}}(\mathscr{\mathscr { C }}), \mu \leq \nu(\mathscr{L})$ or $\nu \leq \mu\left(\mathscr{L}^{\prime}\right)$. Since $\mathscr{L}$ is normal, by proposition 3.3, $\nu \in \mathrm{I}_{o}\left(\mathscr{L}^{\prime}\right)$; therefore, $\nu \in \mathrm{I}_{o}(\mathscr{L})$ because $\mathscr{L}$ is countably paracompact. With $\nu \in I_{R}^{o}(\mathscr{L}), \nu=\nu^{\prime \prime}=\nu^{\prime}(\mathscr{L})$. We also have $\nu^{\prime \prime} \leq \mu^{\prime \prime}(\mathscr{L})$. Combining the above, we have $\mu \leq \nu=\nu^{\prime}=\nu^{\prime \prime} \leq \mu^{\prime \prime} \leq \mu^{\prime}(\mathscr{L})$. Since $\mathscr{L}$ is normal, $\nu \in \mathrm{I}_{\mathrm{R}}(\mathscr{L})$ with $\mu \leq \nu(\mathscr{L})$, we have $\nu^{\prime}=\mu^{\prime}(\mathscr{L})$. Therefore, $\nu^{\prime}=\mu^{\prime \prime}=\mu^{\prime}(\mathscr{L})$.

c. $\mathscr{S}$ is countably compact if and only if $\mathrm{I}(\mathscr{L})=\mathrm{I}_{o}(\mathscr{L})$. If for some $\mathrm{H} \in \mathscr{L}, \mu^{\prime \prime}(\mathrm{H})=0$, then using a finite cover for $\mathrm{X}$ yields a cover for $\mathrm{H}$ in $\mathscr{L}^{\prime}$ with measure zero, so $\mu^{\prime}(\mathrm{H})=0$.

Finally, we introduce the following topological-like concept relating two lattices.

DEFINITION 3.1. The lattice $\mathscr{L}_{1}$ is a sublattice of $\mathscr{L}_{2}, \mathscr{L}_{2}$ is said to be $\underline{\mathscr{L}}_{1}$ countably compact if whenever $\mathrm{L}_{2} \in \mathscr{L}_{2}, \mathrm{~L}_{2} \subseteq \bigcup_{\mathrm{n}} \mathrm{A}_{\mathrm{n}}{ }^{\prime}$ where $\left\{\mathrm{A}_{\mathrm{n}} \in \mathscr{L}_{1}\right\}$, we have $\mathrm{L}_{2} \subseteq \bigcup_{\mathrm{fin}} \mathrm{A}_{\mathrm{n}}{ }^{\prime}$.

NOTE. If $\mathscr{L}_{2}$ is $\mathscr{L}_{1}$ countably compact, then $\mathscr{L}_{1}$ is countably compact because $\mathrm{X} \in \mathscr{L}_{2}$.

PROPOSITION 3.5. (a) If $\mu \in \mathrm{I}_{\sigma}\left(\mathscr{L}_{1}\right), \mathscr{L}_{2}$ is $\mathscr{L}_{1}$ countably compact (so $\mathrm{I}\left(\mathscr{L}_{1}\right)=\mathrm{I}_{\sigma}\left(\mathscr{L}_{1}\right)$ ), then $\mu^{\prime}=\mu^{\prime \prime}\left(\mathscr{L}_{2}\right)$.

(b) If $\mathscr{L}_{2}$ is $\mathscr{L}_{1}$ countably compact, $\mathscr{L}_{1}$ is complement generated and normal (so $\left.\mathrm{I}_{\mathrm{R}}\left(\mathscr{L}_{1}\right)=\mathrm{I}_{\mathrm{R}}^{0}\left(\mathscr{L}_{1}\right)\right)$, and $\mu \in \mathrm{I}_{\mathrm{R}}\left(\mathscr{L}_{1}\right)$, then $\mu^{\prime}=\tilde{\mu}\left(\mathscr{L}_{2}\right)$ and $\mathscr{L}_{1}$ semi-separates $\mathscr{L}_{2}$.

PROOF. a. For $\mu \in \mathrm{I}_{o}\left(\mathscr{L}_{1}\right), \mu^{\prime \prime}(\mathrm{E}) \leq \mu^{\prime}(\mathrm{E})$ for all $\mathrm{E} \subseteq \mathrm{X}$. Equality follows because there is a finite cover for any covering in the definition of $\mu^{\prime \prime}(\mathrm{E})$.

b. In the proof of proposition $2.2 \mathrm{a}$, we see that $\mu^{\prime}\left(\mathrm{L}_{2}\right) \leq \tilde{\mu}\left(\mathrm{L}_{2}\right)$ for any $\mathrm{L}_{2} \in \mathscr{L}_{2}$ because $\mu=\mu^{\prime}\left(\mathscr{L}_{1}\right)$ when $\mu \in \mathrm{I}_{\mathrm{R}}\left(\mathscr{L}_{1}\right)$. Now if $\mu^{\prime}(\mathrm{E})=0$ for some $\mathrm{E} \in \mathscr{L}_{2}$, then $\mathrm{E} \subseteq \mathrm{A}^{\prime}$ for some $\mathrm{A} \in \mathscr{L}_{1}$ and $\mu\left(\mathrm{A}^{\prime}\right)=0$. Since $\mathrm{A}=\bigcap_{\mathrm{n}} \mathrm{L}_{\mathrm{n}}{ }^{\prime} \subseteq \mathrm{L}_{\mathrm{n}}{ }^{\prime} \in \mathscr{L}_{1}{ }^{\prime}$, we may use normality to arrive at $\tilde{\mu}(\mathrm{E})=0$. Therefore, $\mu^{\prime}=\tilde{\mu}\left(\mathscr{L}_{2}\right)$ and by proposition $2.2, \mathscr{L}_{1}$ semi-separates $\mathscr{L}_{2}$.

\section{SLIGHTLY REGULAR MEASURES AND OUTER MEASURABLE SETS.}

To continue investigating the relationship between the two outer measures, $\mu^{\prime}$ and $\mu^{\prime \prime}$, we consider first the notion of a slightly regular measure introduced in [4]. We review some of its properties and extend the work done in $[4,5,6,7]$.

DEFINITION 4.1: A $\sigma$-smooth measure $\mu \in \mathrm{I}_{o}(\mathscr{L})$ is said to be slightly regular on $\mathscr{L}, \mu \in \mathrm{I}_{\mathrm{o}}(\mathscr{L})$, if $\mu\left(L^{\prime}\right)=1$ for some $L \in \mathscr{L}$ implies that there exists a sequence $\left\{L_{n} \in \mathscr{L}\right\}$ such that $L^{\prime} \supseteq \bigcap_{n} L_{n}$ and $\mu\left(\mathrm{L}_{\mathfrak{n}}\right)=1$ for all $\mathrm{n}$.

\section{Properties of $\mu \in \mathrm{L},(\mathscr{L})$ :}

(1) $\mu \in \mathrm{I}_{\mathrm{s}}(\mathscr{L})$ if and only if $\mu=\mu^{\prime \prime}(\mathscr{L})$.

PROOF. a. Suppose $\mu \in \mathrm{I}_{\mathrm{s}}(\mathscr{L})$. In general, $\mu \leq \mu^{\prime \prime}(\mathscr{L})$. Now if there exists $\mathrm{L} \in \mathscr{L}$ with 
$\mu(\mathrm{L})=0$, then $\mu\left(\mathrm{L}^{\prime}\right)=1$ and there is a sequence $\left\{\mathrm{L}_{\mathrm{n}} \in \mathscr{\varphi}\right\}$ such that $\mathrm{L}^{\prime} \supseteq \mathrm{L}_{\mathrm{n}}$ and $\mu\left(\mathrm{L}_{\mathrm{n}}\right)=1$ for all $\mathrm{n}$. Then $\mu^{\prime \prime}(\mathrm{L})=0$.

b. Suppose $\mu=\mu^{\prime \prime}\left(\varphi^{\prime}\right)$ and $\mu\left(\mathrm{A}^{\prime}\right)=1$ for some $\mathrm{A} \in \mathcal{S}^{\circ}$. Then $\mu^{\prime \prime}(\mathrm{A})=\mu(\mathrm{A})=0$ and from the definition of $\mu^{\prime \prime}$, we arrive at $\mu \in \mathrm{I}_{\mathrm{s}}(\varphi)$.

For $\mu \in I_{o}(\mathscr{Y}), \mu^{\prime \prime}$ on the intersection of a sequence of sets in $\mathscr{\varphi}$, each with measure 1 , is 1 . The converse is true if $\mu \in \mathrm{I}_{\mathrm{s}}(\mathscr{X})$ :

(2) If $\mu \in \mathrm{I}_{\mathrm{s}}(\mathscr{\varphi})$ and $\mu^{\prime \prime}\left(\bigcap_{\mathrm{n}} \mathrm{L}_{\mathrm{n}}\right)=1$ with $\mathrm{L}_{\mathrm{n}} \in \mathscr{S}$. for all $\mathrm{n}$, then $\mu\left(\mathrm{L}_{\mathrm{n}}\right)=1$ for all $\mathrm{n}$.

PROOF. If $\mu^{\prime \prime}\left(\cap_{\mathrm{n}} \mathrm{L}_{\mathrm{n}}\right)=1$, then $\mu^{\prime \prime}\left(\mathrm{L}_{\mathrm{n}}\right)=1$ for all $\mathrm{n}$. So $\mu\left(\mathrm{L}_{\mathrm{n}}\right)=\mu^{\prime \prime}\left(\mathrm{L}_{\mathrm{n}}\right)=1$ for all $\mathrm{n}$.

(3) If $\mu \in I_{R}^{0}(\mathscr{L})$, then $\mu \in I_{s}(\mathscr{S})$.

(4) If $\mu \in \mathrm{I}_{\mathrm{s}}(\mathscr{L})$, then $\mu \in \Phi(\mathscr{L})$.

PROOF. Suppose there exists a sequence $\left\{\mathrm{L}_{\mathrm{n}} \in \mathscr{L}\right\}, \mathrm{L}_{\mathrm{n}} \downarrow \bigcap_{\mathrm{n}} \mathrm{L}_{\mathrm{n}}=\mathrm{L} \in \mathscr{L}, \mu\left(\mathrm{L}_{\mathrm{n}}\right)=1$ for all $\mathrm{n}$ but $\mu(\mathrm{L})=0$. Since $\mu\left(\mathrm{L}^{\prime}\right)=1$, there exists $\left\{\mathrm{A}_{\mathrm{n}} \in \mathscr{L}\right\}$ such that $\mathrm{L} \subseteq \bigcup_{\mathrm{n}} \mathrm{A}_{\mathrm{n}}{ }^{\prime}$ and $\mu\left(\mathrm{A}_{\mathrm{n}}{ }^{\prime}\right)=0$ for all $\mathrm{n} ; \mu^{\prime \prime}(\mathrm{L})=0$. Also, $\mathrm{L}^{\prime}=\bigcup_{\mathrm{n}} \mathrm{L}_{\mathrm{n}}{ }^{\prime}$ and $\mu\left(\mathrm{L}_{\mathrm{n}}{ }^{\prime}\right)=0$ for all $\mathrm{n} ; \mu^{\prime \prime}\left(\mathrm{L}^{\prime}\right)=0$. Hence $\mu^{\prime \prime} \equiv 0$, contradicting that $\mu \in \mathrm{I}_{o}(\mathscr{S})$.

(5) If $\mathscr{L}$ semi-separates $\delta(\mathscr{L})$, where $\delta(\mathscr{\varphi})$ is the lattice of all countable intersections of sets from $\mathscr{L}$, and if $\mu \in I_{s}(\mathscr{L})$, then $\mu \in I_{R}^{\sigma}(\mathscr{L})$.

To see the relationship between strongly $\sigma$-smoothness and slightly regularity, recall that in the classical case, for an outer measure $\mu^{*}$, a set $\mathrm{E} \subseteq \mathrm{X}$ is said to be $\mu^{*}$-measurable if for any $\mathrm{A} \subseteq \mathrm{X}$, $\mu^{*}(\mathrm{~A})=\mu^{*}(\mathrm{~A} \cap \mathrm{E})+\mu^{*}\left(\mathrm{~A} \cap \mathrm{E}^{\prime}\right) \quad\left(\mathrm{E}\right.$ splits all sets additively with respect to $\left.\mu^{*}\right)$. Here we will call the sets of all $\mu^{\prime}$-measurable and $\mu^{\prime \prime}$-measurable sets $\mathbf{S}_{\mu^{\prime}}$ and $\mathbf{S}_{\mu^{\prime \prime}}$ respectively. As in the classical case, $\mathbf{S}_{\mu^{\prime \prime}}$ is closed under complement and countable union, while $\mathbf{S}_{\mu^{\prime}}$ is an algebra; any set with outer measurable zero is measurable. The restriction of $\mu^{\prime}$ on $\mathbf{S}_{\mu^{\prime}}$ is finitely additive and the restriction of $\mu^{\prime \prime}$ on $\mathrm{S}_{\mu^{*}}$ is countably additive. Recall also that an outer measure $\mu^{*}$ is said to be regular if for all $\mathrm{A} \subseteq \mathrm{X}$, there is a $\mu^{*}$-measurable set $\mathrm{E} \supseteq \mathrm{A}$ such that $\mu^{*}(\mathrm{E})=\mu^{*}(\mathrm{~A})$; $\mathrm{E}$ is called a measurable cover for $\mathrm{A}$. There is a duality between statements on $\mu^{\prime}, \mu^{\prime \prime}$ and those on $\tilde{\mu}$ and $\tilde{\tilde{\mu}}$.

\section{Remarks:}

(1) For $\mu \in \mathrm{I}(\mathscr{L}), \mathrm{S}_{\mu^{\prime}}=\{\mathrm{E} \subseteq \mathrm{X}$ : there exists $\mathrm{L} \in \mathscr{L}$ such that $\mathrm{E} \supseteq \mathrm{L}$ with $\mu(\mathrm{L})=1$ or such that $\mathrm{E}^{\prime} \supseteq \mathrm{L}$ with $\left.\mu(\mathrm{L})=1\right\}$ and $\mathrm{S}_{\boldsymbol{\mu}}=\left\{\mathrm{E} \subseteq \mathrm{X}\right.$ : there exists $\mathrm{L} \in \mathscr{L}$ such that $\mathrm{E} \supseteq \mathrm{L}^{\prime}$ with $\mu\left(\mathrm{L}^{\prime}\right)=1$ or such that $\mathrm{E}^{\prime} \supseteq \mathrm{L}^{\prime}$ with $\left.\mu\left(\mathrm{L}^{\prime}\right)=1\right\}$.

PROOF. a. Suppose $\mathrm{E} \in \mathrm{S}_{\mu^{\prime}}$. If $\mu^{\prime}(\mathrm{E})=0$, we have $\mathrm{L} \in \mathscr{L}$ such that $\mathrm{E} \subseteq \mathrm{L}^{\prime}$ and $\mu\left(\mathrm{L}^{\prime}\right)=0$, or $\mathrm{L} \subseteq \mathrm{E}^{\prime}$ and $\mu(\mathrm{L})=1$. If $\mu^{\prime}(\mathrm{E})=1$, since $\mu^{\prime}(\mathrm{X})=\mu^{\prime}(\mathrm{E})+\mu^{\prime}\left(\mathrm{E}^{\prime}\right)$, we have $\mu^{\prime}\left(\mathrm{E}^{\prime}\right)=0$. Again, there exists $\mathrm{L} \in \mathscr{L}$ such that $\mathrm{E}^{\prime} \subseteq \mathrm{L}^{\prime}$ and $\mu\left(\mathrm{L}^{\prime}\right)=0$, or $\mathrm{L} \subseteq \mathrm{E}$ and $\mu(\mathrm{L})=1$.

b. Let $\mathrm{E}$ be in the right-hand side set. If $\mathrm{E} \supseteq \mathrm{L} \in \mathscr{L}$ with $\mu(\mathrm{L})=1$, then $\mathrm{E}^{\prime} \subseteq \mathrm{L}^{\prime}$ and $\mu\left(\mathrm{L}^{\prime}\right)=0$. So $\mu^{\prime}\left(\mathrm{E}^{\prime}\right)=0$ and $\mathrm{E}^{\prime} \in \mathrm{S}_{\mu^{\prime}}$; therefore $\mathrm{E} \in \mathrm{S}_{\mu^{\prime}}$. If $\mathrm{E}^{\prime} \supseteq \mathrm{L} \in \mathscr{L}$ with $\mu(\mathrm{L}-)=1$, then $\mu^{\prime}(\mathrm{E})=0$ and $\mathrm{E} \in \mathrm{S}_{\mu^{\prime}}$.

The second part of the statement follows by replacing $\mathscr{L}$ by $\mathscr{L}^{\prime}$.

(2) For $\mu \in I_{o}(\mathscr{L}), S_{\mu^{*}}=\left\{E \subseteq X\right.$ : there exists $\left\{L_{n} \in \mathscr{L}\right\}$ such that $E \supseteq \bigcap_{n} L_{n}$ with $\mu\left(L_{n}\right)=1$ for all $\mathrm{n}$ or such that $\mathrm{E}^{\prime} \supseteq \bigcap_{\mathrm{n}} \mathrm{L}_{\mathrm{n}}$ with $\mu\left(\mathrm{L}_{\mathrm{n}}\right)=1$ for all $\left.\mathrm{n}\right\}$ and $\mathrm{S}_{\tilde{p}}=\{\mathrm{E} \subseteq \mathrm{X}$ : there exists $\left\{L_{n} \in \mathscr{L}\right\}$ such that $E \supseteq \bigcap_{n}^{n} L_{n}{ }^{\prime}$ with $\mu\left(L_{n}{ }^{\prime}\right)=1$ for all $n$ or such that $E^{\prime} \supseteq \bigcap_{n} L_{n}{ }^{\prime}$ with $\mu\left(L_{n}{ }^{\prime}\right)=1$ for all $\left.\mathrm{n}\right\}$.

PROOF. Omitted. 
(3) If $\mu \in \mathrm{I}(\mathscr{P})\left[\mathrm{I}_{o}(\mathscr{L})\right]$, then $\mu^{\prime}\left[\mu^{\prime \prime}\right]$ is a regular outer measure.

In our case of 0-1 measures, to see whether a set is measurable, it suffices to check the equation on the set $\mathrm{X}$ :

(4) For $\mu \in \mathrm{I}(\mathscr{\mathscr { S }})$ and $\mathrm{E} \subseteq \mathrm{X}$, if $\mu^{\prime}(\mathrm{X})=\mu^{\prime}(\mathrm{E})+\mu^{\prime}\left(\mathrm{E}^{\prime}\right)$, then $\mathrm{E} \in \mathbf{S}_{\mu^{\prime}}$. The statement is true for $\mu \in \mathrm{I}_{o}\left(\mathscr{S}_{)}\right)$and $\mu^{\prime}$ is replaced by $\mu^{\prime \prime}, \mathbf{S}_{\mu^{\prime}}$ by $\mathbf{S}_{\mu^{\prime \prime}}$.

(5) If $\mu \in \mathrm{I}_{\text {, }}(\mathscr{Q})$, then $\mu=\mu^{\prime \prime}{ }_{\mid \mathbf{A}(\mathscr{Q})}$ and $\mu \in \mathrm{I}^{\circ}(\mathscr{Q})$.

PROOF. For any $\mathrm{L} \in \mathscr{S}$, we have $\mu(\mathrm{X})=\mu(\mathrm{L})+\mu\left(\mathrm{L}^{\prime}\right)$. Since $\mu \in \mathrm{I}_{\mathrm{s}}(\mathscr{L}), \mu=\mu^{\prime \prime}(\mathscr{L})$; $\mu^{\prime \prime} \leq \mu\left(\mathscr{L}^{\prime}\right)$. The above equation gives $\mu^{\prime \prime}(\mathrm{X}) \geq \mu^{\prime \prime}(\mathrm{L})+\mu^{\prime \prime}\left(\mathrm{L}^{\prime}\right)$. So $\mathrm{L} \in \mathrm{S}_{\mu^{\prime \prime}}$; or $\mathscr{L} \subseteq \mathrm{S}_{\mu^{\prime \prime}}$ which is an algebra and therefore contains $A(\mathscr{L})$. The restriction of $\mu^{\prime \prime}$ is a measure on $\mathbf{S}_{\mu^{*}}$ and therefore on $\mathbf{A}(\mathscr{L})$. Since $\mu=\mu^{\prime \prime}(\mathscr{\mathscr { C }}), \mu=\mu^{\prime \prime}{ }_{\mid \mathbf{A}(\mathscr{Q})}$. The latter is countably additive, so $\mu \in \mathrm{I}^{\circ}(\mathscr{L})$.

A series of statements using measurable sets lead to an alternate proof of proposition 3.2:

PROPOSITION 4.1. (a) Suppose $\mu \in \mathrm{I}_{o}(\mathscr{L})$ where $\mathscr{L}$ is normal. If $\mathrm{A} \in \mathscr{L}$ and $\mathrm{A}=\bigcap_{\mathrm{n}} \mathrm{B}_{\mathrm{n}}{ }^{\prime}$ where $\mathrm{B}_{\mathrm{n}} \in \mathscr{L}$, then $\mathrm{A} \in \mathrm{S}_{\mu^{\prime \prime}}$.

(b) Suppose $\mu \in \Phi(\mathscr{L})$ where $\mathscr{L}$ is normal and countably paracompact. If $\mathrm{A} \in \mathscr{L}$ and $\mathrm{A}=\bigcap_{\mathrm{n}} \mathrm{B}_{\mathrm{n}}{ }^{\prime}$ where $\mathrm{B}_{\mathrm{n}} \in \mathscr{L}$, then $\mathrm{A} \in \mathrm{S}_{\mu^{\prime}}$.

(c) If $\mu \in \Phi(\mathscr{L})$ where $\mathscr{L}$ is normal and complement generated, then $\mu \in I_{\mathrm{R}}^{\sigma}(\mathscr{L})$. [proposition

PROOF. a. Since $\mathrm{A} \subseteq \mathrm{B}_{\mathrm{n}}{ }^{\prime}$ and $\mathscr{L}$ is normal, there exists $\mathrm{C}_{\mathrm{n}}$ and $\mathrm{D}_{\mathrm{n}}$ in $\mathscr{L}$ such that $A \subseteq C_{n}{ }^{\prime} \subseteq D_{n} \subseteq B_{n}{ }^{\prime}$ for all $n$. So we have $A=\bigcap_{n} C_{n}{ }^{\prime}=\bigcap_{n} D_{n}=\bigcap_{n} B_{n}{ }^{\prime}$. Sets of $\mu^{\prime \prime}$-measure zero are in $\mathrm{S}_{\mu^{\prime \prime}}$. If $\mu^{\prime \prime}(\mathrm{A})=1$, then $\mu^{\prime \prime}\left(\mathrm{C}_{\mathrm{n}}{ }^{\prime}\right)=1$; Since $\mu^{\prime \prime} \leq \mu\left(\mathscr{L}^{\prime}\right), \mu\left(\mathrm{C}_{\mathrm{n}}{ }^{\prime}\right)=1$ and therefore $\mu\left(\mathrm{D}_{\mathrm{n}}\right)=1$ for all $\mathrm{n}$. Now $\mathrm{A}=\bigcap_{\mathrm{n}} \mathrm{D}_{\mathrm{n}}$ and $\mu\left(\mathrm{D}_{\mathrm{n}}\right)=1$ for all $\mathrm{n}$, so $\mathrm{A} \in \mathbf{S}_{\mu^{\prime \prime}}$.

b. By normality and countably paracompactness, $\mu^{\prime}=\mu^{\prime \prime}(\mathscr{L})$. If $\mu^{\prime}(\mathrm{A})=1$, then $\mu^{\prime \prime}(\mathrm{A})=1$ and A $\in \mathbf{S}_{\mu^{*}}$ by part a. In this case $\mathbf{S}_{\mu^{*}} \cap \mathscr{L}=\mathrm{S}_{\mu^{\prime}} \cap \mathscr{L}$, so $\mathrm{A} \in \mathrm{S}_{\mu^{\prime}}$.

c. We have therefore $\mathscr{L}$ is countably paracompact and normal and $\mathscr{L} \subseteq \mathrm{S}_{\mu^{\prime}}$. Since $\mathrm{S}_{\mu^{\prime}} \cap \mathscr{L}=\left\{\mathrm{L} \in \mathscr{L}: \mu^{\prime}(\mathrm{L})=\mu(\mathrm{L})\right\}$, so $\mu^{\prime}(\mathrm{L})=\mu(\mathrm{L})$ for all $\mathrm{L} \in \mathscr{L}$, or $\mu=\mu^{\prime}(\mathscr{L})$, or $\mu \in \mathrm{I}_{R}^{o}(\mathscr{L})$.

Using the regularity of the outer measures, we give

ALTERNATE PROOF FOR PROPOSITION 3.2. If $\mathscr{L}$ is normal, $\mu \in \mathrm{I}_{o}(\mathscr{L}), \nu \in \mathrm{I}_{\mathrm{R}}(\mathscr{L})$ and $\mu \leq \nu(\mathscr{L})$, then $\nu \in \mathrm{I}_{\sigma}\left(\mathscr{L}^{\prime}\right)$.

PROOF. We have $\mu \leq \nu=\nu^{\prime} \leq \mu^{\prime}(\mathscr{L})$ and $\mu^{\prime}=\nu^{\prime}(\mathscr{L})$ by normality. Therefore, $\mu \leq \mu^{\prime \prime} \leq \mu^{\prime}=\nu^{\prime}=\nu(\mathscr{L})$. Suppose that for $\left\{L_{n} \in \mathscr{L}\right\}, L_{n}^{\prime} \downarrow \varnothing$. Then $L_{n} \uparrow X$ or $X=\bigcup_{n} L_{n}$ and $1=\mu^{\prime \prime}(X)=\lim _{n \rightarrow \infty} \mu^{\prime \prime}\left(L_{n}\right)$ by the regularity of $\mu^{\prime \prime}$. So there exists $N$ such that $\mu^{\prime \prime}\left(L_{N}\right)=1$ and therefore $\nu\left(\mathrm{L}_{\mathrm{n}}\right)=1$ for $\mathrm{n} \geq \mathrm{N}$, or $\nu^{\prime}\left(\mathrm{L}_{\mathrm{n}}{ }^{\prime}\right)=0$ for $\mathrm{n} \geq \mathrm{N}$. Hence $\nu \in \mathrm{I}_{o}\left(\mathscr{L}^{\prime}\right)$.

PROPOSITION 4.2. If $\mathscr{L}$ is normal and a $\delta$-lattice, $\mu \in \mathrm{I}_{o}(\mathscr{L}), \nu \in \mathrm{I}_{\mathrm{R}}(\mathscr{L})$ and $\mu \leq \nu(\mathscr{L})$, then $\nu \in \Phi\left(\mathscr{L}^{\prime}\right)$.

PROOF. By proposition 3.4a and normality, we have $\mu \leq \mu^{\prime \prime}=\mu^{\prime}=\nu^{\prime}=\nu(\mathscr{L})$. Suppose that for $\left\{\mathrm{L}_{\mathrm{n}} \in \mathscr{L}\right\} \mathrm{L}_{\mathrm{n}}{ }^{\prime} \downarrow \mathrm{L}^{\prime} \in \mathscr{L}^{\prime}$. Then $\mathrm{L}_{\mathrm{n}} \uparrow \mathrm{L}$ and $\mu^{\prime \prime}\left(\mathrm{L}_{\mathrm{n}}\right) \uparrow \mu^{\prime \prime}(\mathrm{L})$, or $\nu\left(\mathrm{L}_{\mathrm{n}}\right) \uparrow \nu(\mathrm{L}), \nu\left(\mathrm{L}_{\mathrm{n}}{ }^{\prime}\right) \downarrow \nu\left(\mathrm{L}^{\prime}\right)$. So $\nu \in \Phi\left(\mathscr{L}^{\prime}\right)$.

PROPOSITION 4.3. If $\mu \in \Phi(\mathscr{L})$ and $\mathscr{L} \subseteq \mathrm{S}_{\mu^{\prime \prime}}$, then $\mu=\mu^{\prime \prime}(\mathscr{L})$ and therefore $\mu \in \mathrm{I}_{\mathbf{3}}(\mathscr{L})$.

PROOF. In general, $\mu \leq \mu^{\prime \prime}(\mathscr{L})$. Suppose that for some $\mathrm{L} \in \mathscr{L}, \mu(\mathrm{L})=0$ and $\mu^{\prime \prime}(\mathrm{L})=1$. 
Since $\mu \in \Phi(\mathscr{L}), \mu^{\prime \prime}\left(\mathrm{L}^{\prime}\right)=\mu^{\prime}\left(\mathrm{L}^{\prime}\right)=\mu\left(\mathrm{L}^{\prime}\right)=1$. But $\mathrm{L}^{\prime}$ is $\mu^{\prime \prime}$-measurable, so $\mu^{\prime \prime}(\mathrm{L})=0$, a contradiction. Therefore, $\mu=\mu^{\prime \prime}\left(\mathscr{\varphi}_{\text {.) }}\right.$ or $\mu \in \mathrm{I}_{\mathrm{s}}\left(\mathscr{Q}_{)}\right)$.

It follows immediately that

COROLLARY. If $\mu \in \Phi\left(\mathscr{L}^{\prime}\right)$ and $\mathscr{Q} \subseteq \mathbf{S}_{\tilde{\mathbf{p}}}$, then $\mu \in \mathrm{I}^{\circ}(\mathscr{\Psi})$.

PROPOSITION 4.4. If $\mu \in \mathrm{I}_{3}(\mathscr{L}), \nu \in \mathrm{I}_{o}(\mathscr{L})$ and $\mu \leq \nu(\mathscr{S})$, then $\nu \in \mathrm{I}_{\mathrm{s}}(\mathscr{S})$.

PROOF. In general, $\nu \leq \nu^{\prime \prime}(\mathscr{L})$. By the definition of the outer measures, $\mu \leq \nu(\mathscr{L})$ implies that $\nu^{\prime \prime} \leq \mu^{\prime \prime}(\mathscr{Q})$. Combining, we have $\mu \leq \nu \leq \nu^{\prime \prime} \leq \mu^{\prime \prime}(\mathscr{Q})$. Since $\mu \in \mathrm{I}_{\mathrm{s}}(\mathscr{L}), \mu=\mu^{\prime \prime}(\mathscr{\mathscr { C }})$; therefore $\nu=\nu^{\prime \prime}(\mathscr{L})$ or $\nu \in \mathrm{I}_{\mathrm{s}}(\mathscr{S})$.

Notes on sets in $\mathscr{L}$ which are measurable:

(1) If $\mu \in \mathrm{I}(\mathscr{S})$, then $\mathbf{S}_{\mu^{\prime}} \cap \mathscr{S}=\left\{\mathrm{L} \in \mathscr{L}: \mu(\mathrm{L})=\mu^{\prime}(\mathrm{L})\right\}$.

(2) For $\mu \in \mathrm{I}_{o}(\mathscr{L}), \mu \in \Phi(\mathscr{L})$ if and only if $\mathrm{S}_{\mu^{\prime \prime}} \cap \mathscr{L}=\left\{\mathrm{L} \in \mathscr{L}: \mu(\mathrm{L})=\mu^{\prime \prime}(\mathrm{L})\right\}$.

PROOF. a. Suppose $\mu \in \Phi(\mathscr{L})$ and $L \in S_{\mu^{*}} \cap \mathscr{L}$. Using Note 5 b on $\sigma$-smoothness, we get $\mu^{\prime \prime}(\mathrm{X})=\mu^{\prime \prime}(\mathrm{L})+\mu^{\prime \prime}\left(\mathrm{L}^{\prime}\right)=\mu^{\prime \prime}(\mathrm{L})+\mu\left(\mathrm{L}^{\prime}\right)$; while $\mu^{\prime \prime}(\mathrm{X})=\mu(\mathrm{X})=\mu(\mathrm{L})+\mu\left(\mathrm{L}^{\prime}\right)$. Therefore $\mu^{\prime \prime}(\mathrm{L})=\mu(\mathrm{L})$.

b. Suppose $\mu \in \Phi(\mathscr{L})$ and $\mathrm{L} \in \mathscr{L}, \mu^{\prime \prime}(\mathrm{L})=\mu(\mathrm{L})$. Then $\mu^{\prime \prime}(\mathrm{X})=\mu(\mathrm{X})=\mu(\mathrm{L})+\mu\left(\mathrm{L}^{\prime}\right)=$ $\mu^{\prime \prime}(\mathrm{L})+\mu^{\prime \prime}\left(\mathrm{L}^{\prime}\right)$, hence $\mathrm{L} \in \mathrm{S}_{\mu^{\prime \prime}}$.

c. Assume that a set in $\mathscr{L}$ is $\mu^{\prime \prime}$-measurable if and only if $\mu^{\prime \prime}$ and $\mu$ have the same value on it. We will show that $\mu^{\prime \prime}=\mu^{\prime}(\mathscr{L})$. In general, $\mu^{\prime \prime} \leq \mu=\mu^{\prime}(\mathscr{L})$. Suppose that for some $\mathrm{L} \in \mathscr{L}$, $\mu^{\prime \prime}\left(\mathrm{L}^{\prime}\right)=0$ and $\mu\left(\mathrm{L}^{\prime}\right)=1$, then $\mu^{\prime \prime}(\mathrm{L})=1$ and $\mu(\mathrm{L})=0$. We have $\mu^{\prime \prime}(\mathrm{X})=1=\mu^{\prime \prime}\left(\mathrm{L}^{\prime}\right)+\mu^{\prime \prime}(\mathrm{L})$; so $\mathrm{L} \in \mathrm{S}_{\mu^{*}}$. We have $\mu(\mathrm{L})=0$ and $\mu^{\prime \prime}(\mathrm{L})=1$, a contradiction.

Recall that $\mu \in \mathrm{I}_{s}(\mathscr{L})$ if and only if for any $\mathrm{L} \in \mathscr{L}, \mu\left(\mathrm{L}^{\prime}\right)=1$ implies that there is a sequence $\left\{L_{n} \in \mathscr{L}\right\}$ such that $L^{\prime} \supseteq \bigcap_{n} L_{n}$ and $\mu\left(L_{n}\right)=1$ for all $n$. By contrast, such a condition for $\mu^{\prime \prime}\left(L^{\prime}\right)=1$ is equivalent to $\mathscr{L} \subseteq \mathbf{S}_{\mu^{*}}$ :

(3) For $\mu \in I_{o}(\mathscr{L}), \mathscr{L} \subseteq S_{\mu^{\prime \prime}}$ if and only if $\mu^{\prime \prime}\left(L^{\prime}\right)=1$ for any $L \in \mathscr{L}$ implies that there is a sequence $\left\{\mathrm{L}_{\mathrm{n}} \in \mathscr{L}\right\}$ such that $\mathrm{L}^{\prime} \supseteq \bigcap_{\mathrm{n}} \mathrm{L}_{\mathrm{n}}$ and $\mu\left(\mathrm{L}_{\mathrm{n}}\right)=1$ for all $\mathrm{n}$.

PROOF. a. Suppose $\mu^{\prime \prime}\left(\mathrm{L}^{\prime}\right)=1$ for some $\mathrm{L} \in \mathscr{L} \subseteq \mathrm{S}_{\mu^{\prime \prime}}$. Then $\mu^{\prime \prime}(\mathrm{L})=0$ and we obtain a sequence $\left\{L_{\mathrm{n}} \in \mathscr{L}\right\}$ such that $\mathrm{L}^{\prime} \supseteq \bigcap_{\mathrm{n}} \mathrm{L}_{\mathrm{n}}$ and $\mu\left(\mathrm{L}_{\mathrm{n}}\right)=1$ for all $\mathrm{n}$.

b. Let $L \in \mathscr{L}$. If $\mu^{\prime \prime}\left(L^{\prime}\right)=0$, then $L^{\prime} \in S_{\mu^{*}}$ and therefore $L \in S_{\mu^{*}}$. If $\mu^{\prime \prime}\left(L^{\prime}\right)=1$, then $L^{\prime} \supseteq \bigcap_{n} L_{n}$ for some $\left\{L_{n} \in \mathscr{L}\right\}$ and $\mu\left(L_{n}\right)=1$ for all $n$. Hence $L \in S_{\mu^{\prime \prime}}$ by Note (2).

A dual statement for $\tilde{\tilde{\mu}}$ follows immediately if we replace $\mathscr{L}$ by $\mathscr{L}^{\prime}$.

(3') For $\mu \in \mathrm{I}_{\sigma}\left(\mathscr{L}^{\prime}\right), \mathscr{L} \subseteq \mathbf{S}_{\tilde{\mu}}$ if and only if $\tilde{\tilde{\mu}}(\mathrm{L})=1$ for any $\mathrm{L} \in \mathscr{L}$ implies that there is a sequence $\left\{\mathrm{L}_{\mathrm{n}} \in \mathscr{L}\right\}$ such that $\mathrm{L} \supseteq \bigcap_{\mathrm{n}} \mathrm{L}_{\mathrm{n}}{ }^{\prime}$ and $\mu\left(\mathrm{L}_{\mathrm{n}}{ }^{\prime}\right)=1$ for all $\mathrm{n}$.

A slightly stronger condition implies that $\mathscr{L} \subseteq \mathbf{S}_{\mu^{n}}$ :

(4) For $\mu \in \mathrm{I}_{o}(\mathscr{L})$, the condition that if $\mu^{\prime \prime}\left(\mathrm{L}^{\prime}\right)=1$ for some $\mathrm{L} \in \mathscr{L}$ then there exists $\tilde{\mathrm{L}} \in \mathscr{L}$ such that $\mathrm{L}^{\prime} \supseteq \tilde{\mathrm{L}}$ and $\mu(\tilde{\mathrm{L}})=1$ implies that $\mathscr{L} \subseteq \mathbf{S}_{\mu^{*}}$. Furthermore, $\mu \leq \mu^{\prime \prime}{ }_{\mid \mathbf{A}(\mathscr{L})}(\mathscr{L})$ and $\boldsymbol{\mu}^{\prime \mathbf{A}(\mathscr{L})} \in \mathrm{I}_{\mathrm{R}}^{\boldsymbol{0}}(\mathscr{L})$.

PROOF. a. If $\mu^{\prime \prime}\left(\mathrm{L}^{\prime}\right)=0$ for some $\mathrm{L} \in \mathscr{L}$, then $\mathrm{L}^{\prime}$ and therefore $\mathrm{L}$ is $\mu^{\prime \prime}$-measurable. If $\mu^{\prime \prime}\left(L^{\prime}\right)=1$, then there exists $\tilde{L} \in \mathscr{L}$ such that $L^{\prime} \supseteq \tilde{L}$ and $\mu(\tilde{L})=1$. Take $L_{n}=\tilde{L}$ for all $n$, then by Note (3) above, $L \in S_{\mu^{\prime \prime}}$. 
b. In general, we have $\mu \leq \mu^{\prime \prime}\left(\mathscr{S}^{\prime}\right)$. We know that $\mu^{\prime \prime}{ }_{\mid \mathbf{A}(\mathscr{L})}$ is a measure on $\mathbf{A}(\mathscr{L})$ because $\mathscr{P} \subseteq \mathbf{S}_{\mu^{\prime \prime}}$ Implies that $\mathbf{A}(\mathcal{H}) \subseteq \mathbf{S}_{\mu^{\prime \prime}}$ and $\mu^{\prime \prime}$ is a measure on $\mathbf{S}_{\mu^{\prime \prime}}$. In this case $\boldsymbol{\mu}^{\prime \prime}{ }_{\mid \mathbf{A}(\mathscr{Q})} \in \mathrm{I}_{\mathbf{R}}^{\mathbf{o}}(\mathscr{L})$ : if $\mu^{\prime \prime}\left(\mathrm{L}^{\prime}\right)=1$ for some $\mathrm{L}^{\prime} \in \mathcal{S}^{\prime}$, then there exists $\tilde{\mathrm{L}} \subseteq \mathrm{L}^{\prime}$ and $\mu^{\prime \prime}(\tilde{\mathrm{L}}) \geq \mu(\tilde{\mathrm{L}})=1$.

(5) If $\mathscr{\varphi}$, is complement generated, then $\mathscr{\varphi} \subseteq \mathbf{S}_{\tilde{\mu}}$.

PROOF. For $L=\bigcap_{n} L_{n}{ }^{\prime}$, if $\tilde{\tilde{\mu}}(L)=\tilde{\tilde{\mu}}\left(\bigcap_{n} L_{n}{ }^{\prime}\right)=1$, then $\tilde{\tilde{\mu}}\left(L_{n}{ }^{\prime}\right)=1$ for all $n$; so $L \in S_{\tilde{\mu}}$.

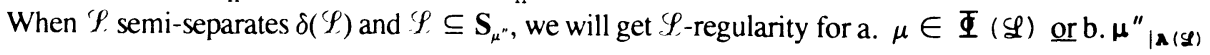
associated with $\mu \in \mathrm{I}_{o}(\varphi)$.

PROPOSITION 4.5. If $\mu \in \Phi(\mathscr{L}), \mathscr{L}$ semi-separates $\delta(\mathscr{L})$ and $\mathscr{L} \subseteq \mathbf{S}_{\mu^{\prime \prime}}$, then $\mu \in \mathrm{I}_{\mathrm{R}}^{o}(\mathscr{L})$.

PROOF. Suppose $\mathrm{A} \in \mathscr{S}$ and $\mu\left(\mathrm{A}^{\prime}\right)=1$. Since $\mu \in \Phi(\mathscr{L})$ and $\mathscr{L} \subseteq \mathbf{S}_{\mu^{\prime \prime}}, \mu \in \mathrm{I}_{\mathrm{s}}(\mathscr{L})$ by proposition 4.3. So there exists $\left\{L_{n} \in \mathscr{L}\right\}$ such that $A^{\prime} \supseteq \bigcap_{n} L_{n}$ and $\mu\left(L_{n}\right)=1$ for all $n$. We have $\mathrm{D}=\bigcap_{\mathrm{n}} \mathrm{L}_{\mathrm{n}} \in \delta(\mathscr{L})$ and $\mathrm{D} \subseteq \mathrm{A}^{\prime}:$ there exists $\tilde{\mathrm{L}} \in \mathscr{L}$ such that $\mathrm{D} \subseteq \tilde{\mathrm{L}} \subseteq \mathrm{A}^{\prime}$ by semi-separateness. It follows from the definition of $\mu^{\prime \prime}$ that $\mu^{\prime \prime}(\mathrm{D})=1$; therefore $1=\mu^{\prime \prime}(\tilde{\mathrm{L}})=\mu(\tilde{\mathrm{L}})$ since $\tilde{\mathrm{L}} \in \mathrm{S}_{\mu^{\prime}}$. So $\mu \in \mathrm{I}_{\mathrm{R}}(\mathscr{L})$.

A dual statement for $\tilde{\tilde{\mu}}$ follows:

COROLlaRY. If $\mu \in \Phi\left(\mathscr{L}^{\prime}\right), \mathscr{L}$ semi-separates $\delta\left(\mathscr{L}^{\prime}\right)$ and $\mathscr{L} \subseteq \mathbf{S}_{\tilde{\mathbf{p}}}$, then $\mu \in \mathrm{I}_{\mathrm{R}}^{\boldsymbol{0}}(\mathscr{L})$.

PROPOSITION 4.6. If $\mu \in \mathrm{I}_{\sigma}(\mathscr{L}), \mathscr{L}$ semi-separates $\delta(\mathscr{L})$ and $\mathscr{L} \subseteq \mathrm{S}_{\mu^{*}}$, then $\mu \leq \mu^{\prime \prime}(\mathscr{L})$ and $\mu^{\prime \prime}{ }_{\mid \mathbf{A}(\boldsymbol{Q})} \in \mathrm{I}_{\mathrm{R}}^{\sigma}(\mathscr{L})$.

PROOF. We have $\mu \leq \mu^{\prime \prime}(\mathscr{L})$ and $\mu^{\prime \prime} \mid \mathbf{A}(\mathscr{Q})$ is a measure by our previous argument. To see that $\mu^{\prime \prime}{ }_{\mid \mathbf{A}(\mathscr{L})} \in \mathrm{I}_{\mathrm{R}}(\mathscr{L})$, let $\mu^{\prime \prime}\left(\mathrm{A}^{\prime}\right)=1$ for some $\mathrm{A} \in \mathscr{L}$. Then by Note 3 above, there exists $\left\{\mathrm{L}_{\mathrm{n}} \in \mathscr{L}\right\}$ such that $A^{\prime} \supseteq \bigcap_{n} L_{n}$ and $\mu\left(L_{n}\right)=1$ for all $n$. As in the above argument, $D=\bigcap_{n} L_{n} \in \delta(\mathscr{L})$ and $\mathrm{D} \subseteq \mathrm{A}^{\prime}$, there exists $\tilde{\mathrm{L}} \in \mathscr{L}$ such that $\tilde{\mathrm{L}} \subseteq \mathrm{A}^{\prime}$ and $\mu^{\prime \prime}(\tilde{\mathrm{L}})=1$.

\section{REFERENCES}

1. ALEXANDROFF, A.D., Additive set functions in abstract spaces, Mat. Sb. (N.S.), $\underline{8},(50),(1940)$, 307-348.

2. BACHMAN, G., \& STRATIGOS, P., On general lattice repleteness and completeness, Illinois J. of Math., 27, no. 4, (1983), 535-561.

3. FROLIK, Z., Prime filters with the C.I.P., Comm. Math. Univ. Carolinae, 13 (1972), 553-575.

4. SIEGEL, D., Outer measures and weak regularity of measures Internat. J. Math. and Math. Sci. (to appear).

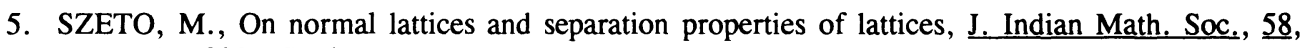
no. 1 (1992), 51-64.

6. SZETO M., On separation of lattices, Internat. J. Math. and Math. Sci., 14, no. 2 (1991), 325-338.

7. VLAD, C., Lattice separation and properties of Wallman type spaces, Annali di Mat. pura ed applicata, (4), vol. 155 (1991), 65-79.

8. WALLMAN, H., Lattices and topological spaces, Ann. of Math., $\underline{39}$ (1938), 112-126. 


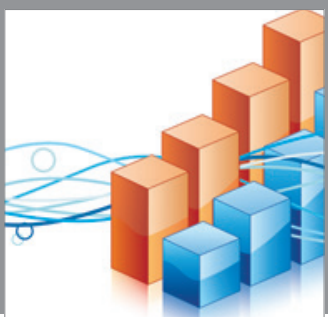

Advances in

Operations Research

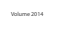

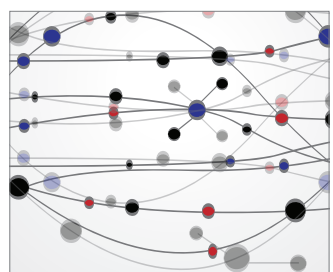

\section{The Scientific} World Journal
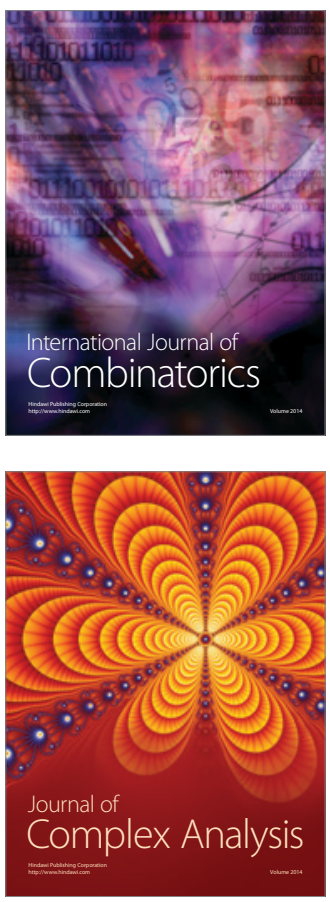

International Journal of

Mathematics and

Mathematical

Sciences
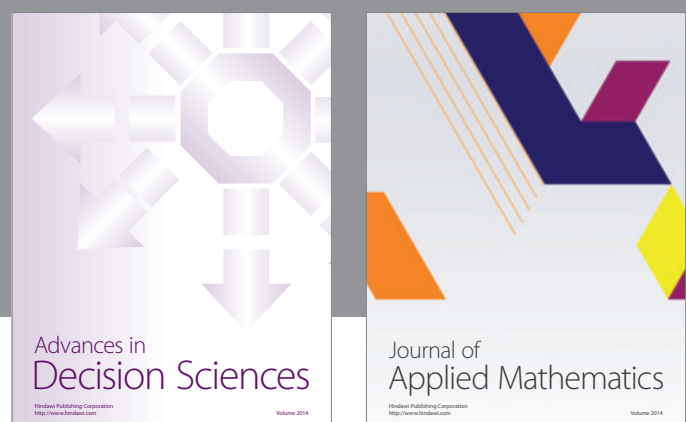

Journal of

Applied Mathematics
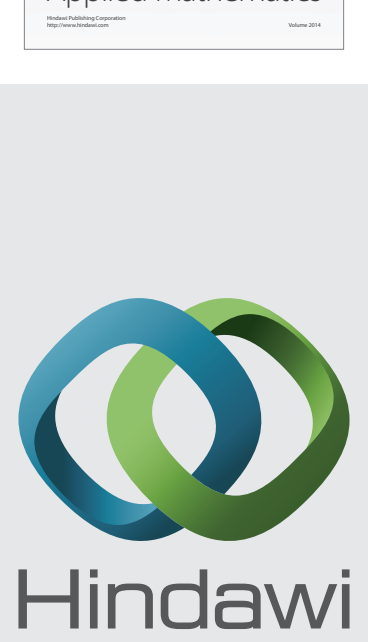

Submit your manuscripts at http://www.hindawi.com
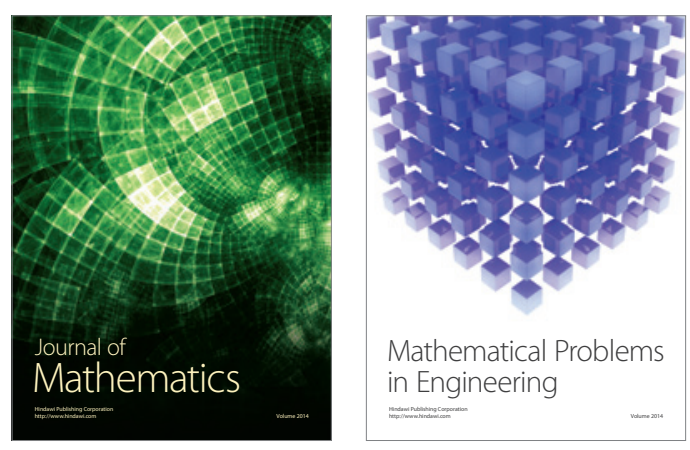

Mathematical Problems in Engineering
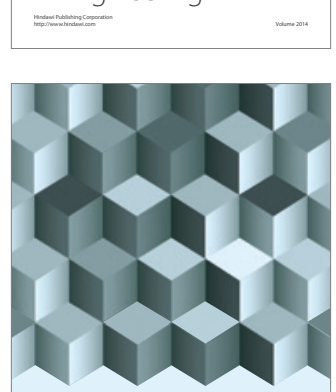

Journal of

Function Spaces
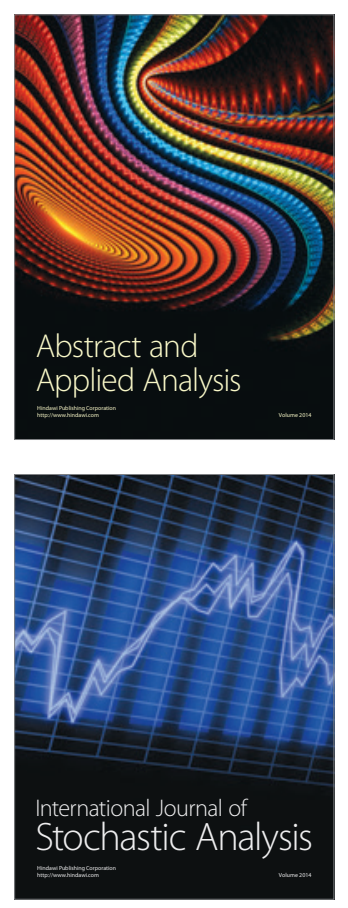

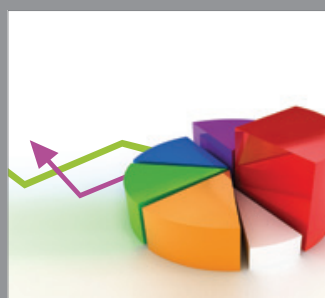

ournal of

Probability and Statistics

Promensencen
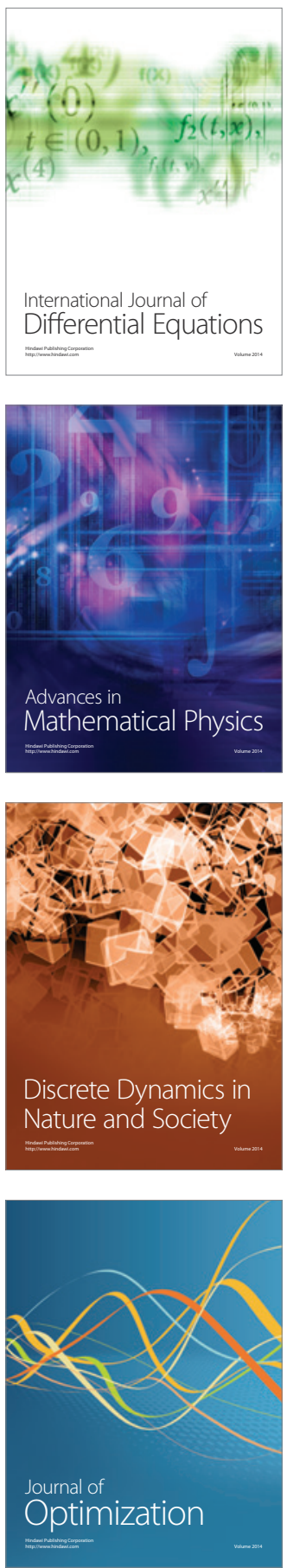